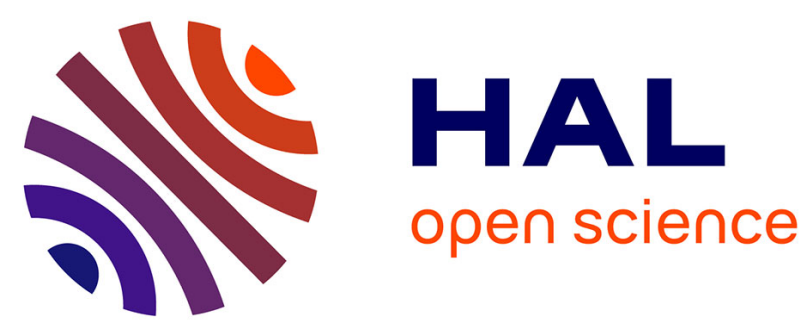

\title{
Genetic diversity of Flavobacterium psychrophilum isolated from rainbow trout in France: predominance of a clonal complex.
}

C Siekoula-Nguedia, Guillaume Blanc, Éric Duchaud, Ségolène Calvez

\section{To cite this version:}

C Siekoula-Nguedia, Guillaume Blanc, Éric Duchaud, Ségolène Calvez. Genetic diversity of Flavobacterium psychrophilum isolated from rainbow trout in France: predominance of a clonal complex.. Veterinary Microbiology, 2012, 161 (1-2), pp.169-78. 10.1016/j.vetmic.2012.07.022 . hal-02652398

\section{HAL Id: hal-02652398 \\ https://hal.inrae.fr/hal-02652398}

Submitted on 29 May 2020

HAL is a multi-disciplinary open access archive for the deposit and dissemination of scientific research documents, whether they are published or not. The documents may come from teaching and research institutions in France or abroad, or from public or private research centers.
L'archive ouverte pluridisciplinaire $\mathbf{H A L}$, est destinée au dépôt et à la diffusion de documents scientifiques de niveau recherche, publiés ou non, émanant des établissements d'enseignement et de recherche français ou étrangers, des laboratoires publics ou privés. 


\title{
Genetic diversity of Flavobacterium psychrophilum isolated from rainbow trout in France: Predominance of a clonal complex
}

\author{
C. Siekoula-Nguedia ${ }^{\mathrm{a}, \mathrm{b}}, \mathrm{G}$ Blanc $^{\mathrm{b}}$, E. Duchaud ${ }^{\mathrm{c}}, \mathrm{S}$. Calvez ${ }^{\mathrm{a}, \mathrm{b}, *}$ \\ a INRA, UMR1300 Biologie, Epidémiologie et Analyse de Risque en santé animale, BP 40706, F-44307 Nantes, France \\ ${ }^{\mathrm{b}}$ LUNAM Université, Oniris, Ecole nationale vétérinaire, agroalimentaire et de l'alimentation Nantes-Atlantique, UMR BioEpAR, F-44307 Nantes, France \\ ' INRA, UR892 Virologie et Immunologie Moléculaires, F-78350 Jouy-en-Josas, France
}

\section{A R T I C L E I N F O}

\section{Article history:}

Received 17 April 2012

Received in revised form 10 July 2012

Accepted 12 July 2012

\section{Keywords:}

Flavobacterium psychrophilum

MLST

Rainbow trout

Salmonid fish

France

\begin{abstract}
A B S T R A C T
Flavobacterium psychrophilum is the causative agent of "bacterial cold water disease" and "rainbow trout fry syndrome" in salmonid farming worldwide. These diseases, especially rainbow trout fry syndrome, are among the main hazards for French aquaculture. In this study, a multilocus sequence typing approach (MLST) was used to evaluate the genetic diversity of this bacterium.

Seven housekeeping genes in a set of 66 isolates were investigated. They were recently collected from rainbow trout during clinical episodes in French farms from the two main geographical areas of production. A total of $5808 \mathrm{bp}$ of sequence were analyzed for each isolate and showed relatively low levels of gene $(H=0.4313)$ and nucleotide $(\pi \times 100=0.31 \%)$ diversities. MLST identified 15 sequence types (STs), of which 14 have never been described. eBURST analysis separated the 15 STs in one clonal complex of 8 genetically related STs (with ST2 as founder) and 7 singletons. Genetic diversity was largely due to recombination, as demonstrated by a pairwise homoplasy index $\left(\mathrm{PHI}=5.35 \times 10^{-9}\right)$ significantly different from zero $(p<0.05)$. The evolution of standardized association index $\left(I_{\mathrm{A}}^{S}\right.$ ) (all isolates: $0.6088, p<0.05$; single representative of STs: $0.4567, p<0.05$; and clusters of STs: $0.084, p>0.05$ ), showed an epidemic structure of the population.

These results emphasized the expansion of a limited number of dominant genetic variants in French clinical $F$. psychrophilum isolates from a single host species, with no geographic relationships.
\end{abstract}

(c) 2012 Elsevier B.V. All rights reserved.

\section{Introduction}

Flavobacterium psychrophilum is a Gram negative bacterium, responsible for rainbow trout fry syndrome (RTFS) and bacterial cold water disease (BCWD), two clinical expressions associated with important economic losses in salmonid fish farming. All salmonid fish

\footnotetext{
* Corresponding author at: Oniris, Ecole nationale vétérinaire, agroalimentaire et de l'alimentation Nantes-Atlantique, UMR INRA-Oniris BioEpAR (Biologie, Epidémiologie et Analyse de Risque en santé animale) F-44307 Nantes, France. Tel.: +33 240687675.

E-mail address: segolene.calvez@oniris-nantes.fr (S. Calvez).
}

(especially coho salmon and rainbow trout) are susceptible to RTFS and BCWD, as well as some other non-salmonid fish, like cyprinids (Lehmann et al., 1991) and pale chub (Zacco platypus) (Iida and Mizokami, 1996). These infections are associated with skin ulcers, necrotic myositis, septicemia as well as exophthalmia (Nematollahi et al., 2003). Vaccines are currently still at the experimental stage (Plant et al., 2009) and treatments rely on antibiotics, with the risk of resistance emergence (Schmidt et al., 2000).

In France, RTFS has been reported as the second major bacteriosis, after furonculosis, affecting breeding fish, particularly rainbow trout, Oncorhynchus mykiss (Walbaum) (Guichard, 2004). The impact of this disease on 
French fish production is considerable, as rainbow trout is the main fish species farmed in France. Information is required about the genetic diversity of $F$. psychrophilum, through the identification of epidemic clones or genetic variants with harmful behavior, in order to define appropriate management strategies to minimize the risks of pathogen introduction or transmission. This knowledge would be useful for future epidemiological monitoring. Several techniques like Random Amplified Polymorphic DNA (RAPD), ribotyping, Fragment Length Polymorphism of PCR products (PCR-RFLP), Pulsed Field Gel Electrophoresis (PFGE), and Multi Locus Sequence Typing (MLST) have been employed to attain this goal (Li et al., 2009).

In this study, we used the previously published MLST scheme (Nicolas et al., 2008) as MLST is a well-established method for characterizing bacterial populations on the basis of sequence polymorphisms on conserved housekeeping genes, and enables easy data sharing (Maiden, 2006). We attempted to assess the genetic diversity of $F$. psychrophilum isolates, recently collected from the main French areas of rainbow trout production (Aquitaine and Bretagne), and some from near-by counties in the Atlantic region of France (Pays de la Loire and Poitou Charente), from rainbow trouts with clinical signs.

\section{Materials and methods}

\subsection{Bacterial isolates and phenotypic identification}

Sixty six F. psychrophilum isolates were sampled between 2007 and 2010 from four French major rainbow trout producing areas, where cases of BCWD and RTFS are regularly reported. Their geographic origins are presented in Fig. 1. Isolates were collected from farmed trouts

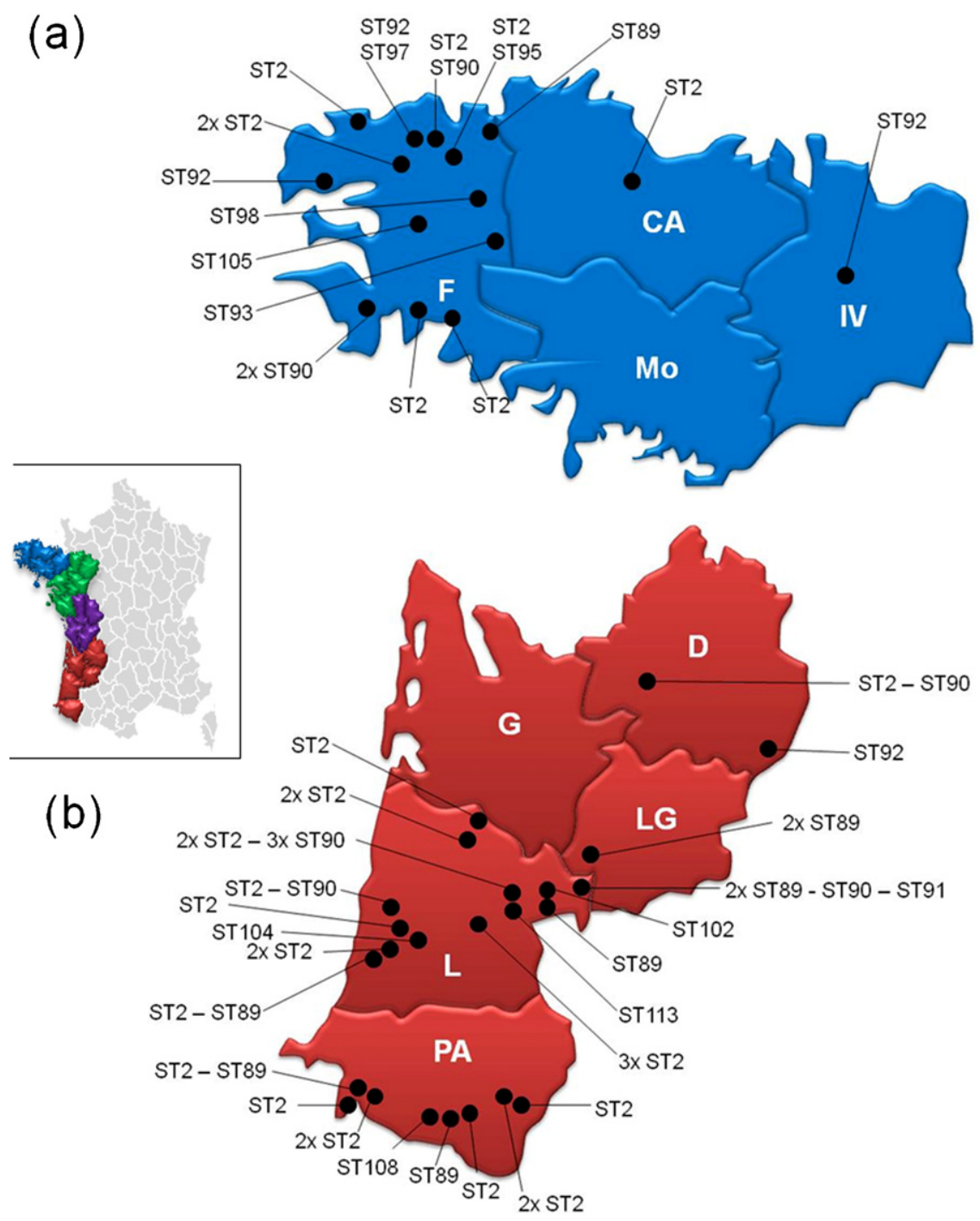

Fig. 1. Geographic origins of French isolates. Regions are indicated by different colours: Bretagne in blue, Pays de la Loire in green, Poitou Charente in violet, and Aquitaine in red. STs recovered from each farm are indicated for the two mains salmonid production regions that are subdivided in departments: (a) Bretagne [Côte d'Armor (CA), Ile et Vilaine (IV), Morbihan (Mo) and Finistère (F)] and (b) Aquitaine [Dordogne (D), Lot et Garonne (LG), Landes (L), Gironde (G) and Pyrénées Atlantiques (PA)]. (For interpretation of the references to color in this figure legend, the reader is referred to the web version of this article.) 
presenting clinical signs of flavobacteriosis, by veterinarians or technicians using different sampling protocols. Therefore, some isolates were collected from internal organs like spleen, kidney, liver, and encephalon, and others from external organs like skin, gills and fin (Table 1). Sometimes several samplings were performed at six or more months intervals at a given site (Fig. 1).
Each isolate was grown on FLP agar medium (Cepeda et al., 2004) at $17{ }^{\circ} \mathrm{C}$ for $48-72 \mathrm{~h}$. A single developed colony was picked from the FLP agar plates and subcultured. The resulting colonies were selected after a preliminary biochemical and phenotypic characterization, based on Gram negative, catalase positive, and flexirubin pigment positive test results.

Table 1

MLST allele types and sequence types of $66 \mathrm{~F}$. psychrophilum isolates. Geographic origins are indicated by region and watershed. Isolates were collected from internal (int), external (ext) or unknown organ (unk), and those included into the clonal complex (CC) are indicated by "in", and the others by "out". New ATs and STs are underlined.

\begin{tabular}{|c|c|c|c|c|c|c|c|c|c|c|c|c|c|}
\hline \multirow[t]{2}{*}{ Isolate } & \multirow{2}{*}{$\begin{array}{l}\text { Geographic } \\
\text { origin }\end{array}$} & \multirow[t]{2}{*}{ Watershed } & \multirow[t]{2}{*}{ Tissue } & \multirow[t]{2}{*}{ Year } & \multicolumn{7}{|c|}{ Allelic profile } & \multirow[t]{2}{*}{ ST } & \multirow[t]{2}{*}{$\mathrm{CC}$} \\
\hline & & & & & $\overline{\operatorname{trp} B}$ & $\operatorname{gyr} B$ & dnak & fumc & murG & tuf & $\overline{\operatorname{atp} A}$ & & \\
\hline 438 & Aquitaine & Adour & int & 2008 & 2 & 2 & 2 & 2 & 2 & 2 & 2 & 2 & in \\
\hline 439 & Aquitaine & Adour & int & 2008 & 2 & 2 & 2 & 2 & 2 & 2 & 2 & 2 & in \\
\hline 440 & Aquitaine & Vignac & int & 2008 & 2 & 2 & 2 & 2 & 2 & 2 & 2 & 2 & in \\
\hline 441 & Aquitaine & Garonne & int & 2008 & 2 & 2 & 2 & 2 & 2 & 47 & 2 & 89 & in \\
\hline 442 & Aquitaine & Vignac & int & 2008 & 1 & 1 & 1 & 1 & 1 & $\overline{2}$ & 1 & $\overline{90}$ & out \\
\hline 444 & Aquitaine & Adour & int & 2008 & 2 & 2 & 2 & 2 & 2 & 2 & 2 & $\overline{2}$ & in \\
\hline 445 & Aquitaine & Adour & int & 2008 & 2 & 2 & 2 & 2 & 2 & 2 & 2 & 2 & in \\
\hline 446 & Aquitaine & Adour & int & 2008 & 2 & 2 & 2 & 2 & 2 & 41 & 2 & 91 & in \\
\hline 448 & Aquitaine & Adour & int & 2008 & 2 & 2 & 2 & 2 & 2 & $\overline{47}$ & 2 & $\overline{89}$ & in \\
\hline 449 & Aquitaine & Adour & int & 2008 & 2 & 2 & 2 & 2 & 2 & $\overline{47}$ & 2 & $\overline{89}$ & in \\
\hline 737 & Aquitaine & Magescq & int & 2008 & 2 & 2 & 2 & 2 & 2 & $\overline{2}$ & 2 & $\overline{2}$ & in \\
\hline 738 & Aquitaine & Adour & ext & 2010 & 1 & 1 & 1 & 1 & 1 & 2 & 1 & $\underline{90}$ & out \\
\hline 739 & Aquitaine & Adour & int & 2009 & 2 & 2 & 2 & 2 & 2 & 47 & 2 & $\overline{89}$ & in \\
\hline 740 & Aquitaine & Adour & ext & 2009 & 2 & 2 & 2 & 2 & 2 & $\overline{2}$ & 2 & $\overline{2}$ & in \\
\hline 742 & Aquitaine & Magescq & int & 2008 & 2 & 2 & 2 & 2 & 2 & 2 & 2 & 2 & in \\
\hline 743 & Aquitaine & Lyere & ext & 2010 & 2 & 2 & 2 & 2 & 2 & 2 & 2 & 2 & in \\
\hline 744 & Aquitaine & Magescq & int & 2008 & 2 & 2 & 2 & 2 & 2 & 2 & 2 & 2 & in \\
\hline 746 & Aquitaine & Adour & int & 2010 & 2 & 2 & 2 & 2 & 2 & 2 & 2 & 2 & in \\
\hline 747 & Aquitaine & Adour & int & 2009 & 2 & 2 & 2 & 2 & 2 & 2 & 2 & 2 & in \\
\hline 749 & Aquitaine & Adour & int & 2009 & 1 & 1 & 1 & 1 & 1 & 2 & 1 & 90 & out \\
\hline 755 & Aquitaine & Adour & int & 2008 & 2 & 2 & 2 & 2 & 2 & 2 & 2 & $\overline{2}$ & in \\
\hline 756 & Aquitaine & Adour & int & 2008 & 2 & $\underline{44}$ & $\underline{16}$ & 3 & 3 & 3 & 3 & $\underline{102}$ & out \\
\hline 759 & Aquitaine & Adour & ext & 2010 & 2 & $\overline{2}$ & $\overline{2}$ & 2 & 2 & 2 & 2 & $\overline{2}$ & in \\
\hline 760 & Aquitaine & Adour & ext & 2009 & 1 & 49 & 10 & 7 & 20 & 25 & $\underline{25}$ & 104 & out \\
\hline 802 & Aquitaine & Garonne & unk & 2010 & 2 & $\overline{2}$ & 2 & 2 & $\overline{2}$ & $\overline{47}$ & $\overline{2}$ & 89 & in \\
\hline 805 & Aquitaine & Dordogne & int & 2009 & 1 & 1 & 1 & 1 & 1 & $\overline{2}$ & 1 & $\overline{90}$ & out \\
\hline 806 & Aquitaine & Adour & int & 2009 & 1 & 1 & 1 & 1 & 1 & 2 & 1 & $\overline{90}$ & out \\
\hline 807 & Aquitaine & Adour & ext & 2010 & 2 & 2 & 2 & 2 & 2 & 2 & 2 & $\overline{2}$ & in \\
\hline 808 & Aquitaine & Adour & ext & 2009 & 2 & 2 & 2 & 2 & 2 & 2 & 2 & 2 & in \\
\hline 810 & Aquitaine & Adour & int & 2009 & 2 & 2 & 2 & 2 & 2 & 2 & 2 & 2 & in \\
\hline 811 & Aquitaine & Lyere & int & 2010 & 2 & 2 & 2 & 2 & 2 & 2 & 2 & 2 & in \\
\hline 812 & Aquitaine & Dordogne & int & 2008 & 2 & 2 & 2 & 2 & 2 & 2 & 2 & 2 & in \\
\hline 814 & Aquitaine & La Palue & int & 2009 & 2 & 2 & 2 & 2 & 2 & 2 & 2 & 2 & in \\
\hline 816 & Aquitaine & Adour & int & 2007 & 2 & 2 & 2 & 2 & 2 & 47 & 2 & $\underline{89}$ & in \\
\hline 817 & Aquitaine & Adour & int & 2010 & 1 & 1 & 1 & 2 & 1 & $\overline{41}$ & 1 & $\underline{108}$ & out \\
\hline 818 & Aquitaine & Lyere & int & 2009 & 2 & 2 & 2 & 2 & 2 & $\overline{2}$ & 2 & $\overline{2}$ & in \\
\hline 820 & Aquitaine & Adour & int & 2007 & 2 & 2 & 2 & 2 & 2 & 2 & 2 & 2 & in \\
\hline 822 & Aquitaine & Lyere & int & 2009 & 3 & 2 & 2 & 2 & 2 & 41 & 2 & 92 & in \\
\hline 823 & Aquitaine & Adour & int & 2010 & 1 & 1 & 1 & 1 & 1 & $\overline{2}$ & 1 & $\overline{90}$ & out \\
\hline 824 & Aquitaine & Adour & int & 2009 & 2 & 2 & 2 & 2 & 2 & 47 & 2 & $\overline{89}$ & in \\
\hline 825 & Aquitaine & Magescq & int & 2009 & 2 & 2 & 2 & 2 & 2 & $\overline{47}$ & 2 & $\overline{89}$ & in \\
\hline 829 & Aquitaine & Adour & ext & 2009 & 4 & 29 & 24 & 5 & 6 & $\overline{49}$ & 40 & 113 & out \\
\hline 539 & Bretagne & Le Guillec & int & 2008 & 3 & $\overline{2}$ & $\overline{2}$ & 2 & 2 & $\overline{41}$ & $\overline{2}$ & 92 & in \\
\hline 540 & Bretagne & Hyere & int & 2008 & 4 & 2 & 2 & 2 & 2 & $\overline{2}$ & 2 & $\overline{93}$ & in \\
\hline 591 & Bretagne & $\begin{array}{l}\text { Rivière de } \\
\text { Morlaix }\end{array}$ & unk & 2009 & 4 & 2 & 2 & 2 & 2 & $\underline{41}$ & 2 & $\overline{95}$ & in \\
\hline 607 & Bretagne & Le Guillec & ext & 2009 & $\underline{29}$ & 2 & 2 & 2 & 2 & 2 & 2 & $\underline{97}$ & in \\
\hline 626 & Bretagne & Penzé & int & 2009 & $\overline{2}$ & 2 & 2 & 2 & 2 & 2 & 2 & $\overline{2}$ & in \\
\hline 635 & Bretagne & Aulne & int & 2008 & 2 & 2 & 2 & 2 & 2 & 48 & 2 & $\underline{98}$ & in \\
\hline 636 & Bretagne & Douron & int & 2008 & 2 & 2 & 2 & 2 & 2 & $\overline{47}$ & 2 & $\overline{89}$ & in \\
\hline 637 & Bretagne & Elorn & int & 2009 & 2 & 2 & 2 & 2 & 2 & $\overline{2}$ & 2 & $\overline{2}$ & in \\
\hline 687 & Bretagne & Elorn & ext & 2009 & 2 & 2 & 2 & 2 & 2 & 2 & 2 & 2 & in \\
\hline 697 & Bretagne & Quillimadec & int & 2010 & 2 & 2 & 2 & 2 & 2 & 2 & 2 & 2 & in \\
\hline 721 & Bretagne & Le Gouët & int & 2010 & 2 & 2 & 2 & 2 & 2 & 2 & 2 & 2 & in \\
\hline
\end{tabular}


Table 1 (Continued)

\begin{tabular}{|c|c|c|c|c|c|c|c|c|c|c|c|c|c|}
\hline \multirow[t]{2}{*}{ Isolate } & \multirow{2}{*}{$\begin{array}{l}\text { Geographic } \\
\text { origin }\end{array}$} & \multirow[t]{2}{*}{ Watershed } & \multirow[t]{2}{*}{ Tissue } & \multirow[t]{2}{*}{ Year } & \multicolumn{7}{|c|}{ Allelic profile } & \multirow[t]{2}{*}{ ST } & \multirow[t]{2}{*}{$\mathrm{CC}$} \\
\hline & & & & & $\operatorname{trp} B$ & gyrB & dnak & fumc & murG & tuf & atpA & & \\
\hline 724 & Bretagne & Ster Goz & int & 2010 & 2 & 2 & 2 & 2 & 2 & 2 & 2 & 2 & in \\
\hline 729 & Bretagne & Penzé & int & 2010 & 1 & 1 & 1 & 1 & 1 & 2 & 1 & $\underline{90}$ & out \\
\hline 730 & Bretagne & Le Corroac'h & int & 2010 & 1 & 1 & 1 & 1 & 1 & 2 & 1 & $\overline{90}$ & out \\
\hline 733 & Bretagne & Unknown & int & 2010 & 3 & 2 & 2 & 2 & 2 & 41 & 2 & $\overline{92}$ & in \\
\hline 763 & Bretagne & Unknown & int & 2010 & 3 & 2 & 2 & 2 & 2 & $\overline{41}$ & 2 & $\overline{92}$ & in \\
\hline 771 & Bretagne & Odet & int & 2010 & 2 & 2 & 2 & 2 & 2 & $\overline{2}$ & 2 & $\overline{2}$ & in \\
\hline 780 & Bretagne & $\begin{array}{l}\text { Rivière de } \\
\text { Morlaix }\end{array}$ & int & 2010 & 2 & 2 & 2 & 2 & 2 & 2 & 2 & 2 & in \\
\hline 787 & Bretagne & Le Corroac'h & int & 2010 & 1 & 1 & 1 & 1 & 1 & 2 & 1 & $\underline{90}$ & out \\
\hline 796 & Bretagne & Douffine & int & 2010 & $\underline{21}$ & 3 & $\underline{22}$ & 3 & 3 & 2 & 2 & $\underline{105}$ & out \\
\hline 690 & Pays de la Loire & $\begin{array}{l}\text { Ruisseau } \\
\text { des Loges }\end{array}$ & ext & 2010 & $\overline{4}$ & $\underline{42}$ & $\overline{21}$ & 5 & 2 & $\underline{39}$ & $\underline{40}$ & $\underline{99}$ & out \\
\hline 718 & Pays de la Loire & Unknown & int & 2010 & 2 & 2 & 2 & 2 & 2 & 2 & 2 & 2 & in \\
\hline 741 & Poitou Charente & Charente & int & 2009 & 1 & 1 & 1 & 1 & 1 & 2 & 1 & $\underline{90}$ & out \\
\hline 745 & Poitou Charente & Charente & int & 2010 & 3 & 2 & 2 & 2 & 2 & 41 & 2 & $\overline{92}$ & in \\
\hline
\end{tabular}

Several bacterial strains were used as control: $F$. psychrophilum reference strains (JIP 02/86, NCIMB $1947^{\mathrm{T}}$ and LNPAA PO1/88), Flavobacterium columnare (NCIMB $2248^{\mathrm{T}}$ ), Flavobacterium johnsoniae (CIP 100931), Flavobacterium aquatile (CIP 103744), Flavobacterium succinicans (CIP 104744), Aeromonas salmonicida (ATCC 14174), Aeromonas hydrophila (CIP 7614) and Escherichia coli (ATCC 25922). All Flavobacteria strains were grown on FLP agar medium at $22^{\circ} \mathrm{C}$ during $72 \mathrm{~h}$, except $F$. psychrophilum cultured at $17^{\circ} \mathrm{C}$ and $F$. johnsoniae cultured during $48 \mathrm{~h}$. Aeromonas and E. coli strains were cultured on trypticase soy agar (TSA) medium at $22^{\circ} \mathrm{C}$ and $37^{\circ} \mathrm{C}$, respectively.

\subsection{DNA extraction and molecular identification of $F$. psychrophilum}

A duplex PCR was developed for the rapid identification of $F$. psychrophilum isolates. This PCR was carried out to amplify gyrA and gyrB genes, using previous designed primer pairs, namely GYRA-FP1F (5'-GAAACCGGTGCACAGAAGG-3') and GYRA-FP1R (5'-CCTGTGGCTCCGTTTATTAA-3') (Izumi and Aranishi, 2004), and PSY-G1F (5'TGCAGGAAATCTTACACTCG-3 $\left.{ }^{\prime}\right)$ and PSY-G1R (5'GTTGCAATTACAATGTTGT-3') (Izumi and Wakabayashi, 2000). The sizes of the expected PCR products were 396 and $1017 \mathrm{bp}$ for gyrA and gyrB genes amplification, respectively. Three $F$. psychrophilum reference strains (JIP 02/86, NCIMB $1947^{\mathrm{T}}$ and LNPAA PO1/88) were used as positive controls in the PCR assays, E. coli was used as negative control, and six other bacterial fish pathogen were used to test the PCR specificity: F. columnare, F. johnsoniae, F. aquatile, F. succinicans, A. salmonicida and A. hydrophila.

Genomic DNA of reference strains and French isolates were extracted and purified using a Wizard genomic DNA purification kit (Promega, France). A $25 \mu \mathrm{L}$ reaction volume contained $5 \mu \mathrm{L}$ of DNA, buffer $1 \mathrm{X}$ (Eurobio, France), $25 \mathrm{pmol}$ of each gyrA primer, $37.5 \mathrm{pmol}$ of each gyrB primer, $200 \mu \mathrm{M}$ of each dNTP, $1.5 \mathrm{mM}$ of $\mathrm{MgCl}_{2}$ and 0.5 units of Taq polymerase (Eurobio, France). The following thermocycling steps were used: $94^{\circ} \mathrm{C}$ for $5 \mathrm{~min}, 35$ cycles consisting of a denaturation step at $94^{\circ} \mathrm{C}$ for $1 \mathrm{~min}$, hybridization at $56{ }^{\circ} \mathrm{C}$ for $1 \mathrm{~min}$ and elongation at $72{ }^{\circ} \mathrm{C}$ for $1.5 \mathrm{~min}$, and a final elongation phase at $72^{\circ} \mathrm{C}$ for $5 \mathrm{~min}$. The products were visualized on a UV transilluminator after separation on a $1.5 \%$ ethidium bromide agarose gel ( $30 \mathrm{~min}$ at $100 \mathrm{~V})$.

\subsection{Multilocus sequence typing}

The seven housekeeping genes (trpB, gyrB, dnaK, fumC, murG, tuf, and atpA) used for the MLST scheme are described in Table 2. They were present in a single copy at each locus and distributed along the chromosome of the reference isolate, JIP 02/86, which is a virulent type isolate of F. psychrophilum (Duchaud et al., 2007). These loci are considered as typical core genome genes with relatively little selective polymorphism and have already been used in MLST studies of some bacteria and particularly of $F$. psychrophilum (Nicolas et al., 2008). The F. psychrophilum reference strain, JIP 02/86 was used as amplification positive control.

Briefly, the amplification mix contained $10 \mu \mathrm{L}$ of genomic DNA (at $\approx 2 n g \mu L^{-1}$ ), GoTaq Green Master Mix $1 \mathrm{X}, 1.87 \mathrm{mM}$ of $\mathrm{MgCl}_{2}, 0.15 \mathrm{mM}$ of each dNTP, $0.25 \mu \mathrm{M}$ of each primer (Table 2) and one unit of Taq DNA polymerase (Promega, France). PCR amplifications were performed in the following conditions: $94{ }^{\circ} \mathrm{C}$ for $5 \mathrm{~min}$, followed by 25 cycles at $94{ }^{\circ} \mathrm{C}$ for $30 \mathrm{~s}, 55^{\circ} \mathrm{C}\left(-0.4{ }^{\circ} \mathrm{C} /\right.$ cycle $)$ for $30 \mathrm{~s}$ and $72{ }^{\circ} \mathrm{C} \mathrm{(+2} \mathrm{s/cycle)} \mathrm{for} 1 \mathrm{~min}$; followed by 12 cycles at $94^{\circ} \mathrm{C}$ for $30 \mathrm{~s}, 45^{\circ} \mathrm{C}$ for $30 \mathrm{~s}$ and $72{ }^{\circ} \mathrm{C}(+3 \mathrm{~s} /$ cycle) for $2 \mathrm{~min}$, and a final extension at $72{ }^{\circ} \mathrm{C}$ for $10 \mathrm{~min}$. Five microliters of the PCR products were resolved on a $1 \%$ ethidium bromide agarose gel to check amplification.

The PCR products were sequenced (LGC Genomics, Berlin) using M13 forward and reverse primers: M13_f, CAGGAAACAGCTATGACC and M13_r, TGTAAAACGACGGCCAGT, included in each specific gene primer (Table 2). The quality of the resulting chromatograms was checked visually and sequences of each locus of each isolate were assembled with Phred and Phrap programs (Ewing and Green, 1998; Ewing et al., 1998). The sequences were trimmed and aligned using respectively Consed (version 
Table 2

Housekeeping genes analyzed in this MLST study, primers and amplicon sizes.

\begin{tabular}{|c|c|c|c|c|c|}
\hline Locus & Gene product & Primers & Sequence $\left(5^{\prime}-3^{\prime}\right)$ & $\begin{array}{l}\text { Size of PCR } \\
\text { amplicon (bp) }\end{array}$ & $\begin{array}{l}\text { Length of the target } \\
\text { sequence (bp) }\end{array}$ \\
\hline $\operatorname{trpB}$ & Tryptophan synthase beta subunit & $\begin{array}{l}\text { trpB_f } \\
\text { trpB_r }\end{array}$ & $\begin{array}{l}\text { M13-f_AAGATTATGTAGGCCGCCC } \\
\text { M13-r_TGATAGATTGATGACTACAATATC }\end{array}$ & 976 & 789 \\
\hline gyrB & DNA gyrase B subunit & $\begin{array}{l}\text { gyrB_f } \\
\text { gyrB_r }\end{array}$ & $\begin{array}{l}\text { M13-f_GTTGTAATGACTAAAATTGGTG } \\
\text { M13-r_CAATATCGGCATCACACAT }\end{array}$ & 1260 & 1077 \\
\hline dnaK & Chaperone protein & $\begin{array}{l}\text { dnaK_f } \\
\text { dnaK_r }\end{array}$ & $\begin{array}{l}\text { M13-f_AAGGTGGAGAAATTAAAGTAGG } \\
\text { M13-r_CCACCCATAGTTTCGATACC }\end{array}$ & 1068 & 882 \\
\hline tuf & Elongation factor $\mathrm{Tu}$ & $\begin{array}{l}\text { tuf_f } \\
\text { tuf_r }\end{array}$ & $\begin{array}{l}\text { M13-f_GAAGAAAAAGAAAGAGGTATTAC } \\
\text { M13-r_CACCTTCACGGATAGCGAA }\end{array}$ & 981 & 795 \\
\hline fumc & Fumarate hydratase class II & $\begin{array}{l}\text { fumC_f_new } \\
\text { fumC_r_new }\end{array}$ & $\begin{array}{l}\text { M13-r_CCAGCAAACAAATACTGGGG } \\
\text { M13-f_GGTTTACTTTTCCTGGCATGAT }\end{array}$ & 936 & 750 \\
\hline murG & $\begin{array}{l}\text { Undecaprenyldiphospho- } \\
\text { muramoylpentapeptide beta-N } \\
\text { acetylglucosaminyltransferase }\end{array}$ & $\begin{array}{l}\text { murG_f } \\
\text { murG_r }\end{array}$ & $\begin{array}{l}\text { M13-f_TGGCGGTACAGGAGGACATAT } \\
\text { M13-r_GCATTCTTGGTTTGATGGTCTTC }\end{array}$ & 869 & 681 \\
\hline $\operatorname{atp} A$ & ATP synthase alpha subunit & $\begin{array}{l}\text { atpA_f } \\
\text { atpA_r }\end{array}$ & $\begin{array}{l}\text { M13-f_CTTGAAGAAGATAATGTGGG } \\
\text { M13-r_TGTTCCAGCTACTTTTTTCAT }\end{array}$ & 1019 & 834 \\
\hline
\end{tabular}

22.0) (Gordon et al., 1998) and BioEdit (version 7.0.5.3) (Hall, 1999) softwares. The resulting sequences were chosen to be shorter than in the initial MLST scheme (Nicolas et al., 2008) to automate the trimming process and ensure the maintenance of good sequence quality.

The nucleotide sequences of each housekeeping gene used for MLST were assigned allele numbers according to the MLST web site (http://www.pasteur.fr/recherche/ genopole/PF8/mlst/Flavopsy.html). The numbered allele types (AT) at each locus of each isolate were combined in order to define a sequence type (ST).

\subsection{Population genetic analysis}

Each MLST locus was analyzed for descriptive characteristics, such as the number of polymorphic sites and the nucleotide diversity per site $(\pi)$, performed by DnaSP version 5.10.01 (Librado and Rozas, 2009). The gene diversity $(H)$ determined using LIAN 3.5 (http:// pubmlst.org/analysis/), was calculated as: $H=[n]$ $\left.(n-1)]\left(1-p_{i}^{2}\right)\right]$, in which $\mathrm{n}$ is the number of samples and $p_{i}$, the relative frequency of the $i$ th allele. The number of synonymous and non-synonymous mutations were counted using MEGA5 software (Tamura et al., 2011). The average non-synonymous/synonymous mutations ratio $(\mathrm{d} N / \mathrm{d} S)$ and the linkage disequilibrium between alleles at the seven gene loci which is measured by standardized index of association $\left(I_{\mathrm{A}}^{\mathrm{S}}\right)$ were calculated with START2 software (Jolley et al., 2001). The index of association provides an indication of the recombination events that have generated genetic variability, as pairwise homoplasy index (PHI) (Bruen et al., 2006) calculated by SplitsTree 4 version 4.12 .3 (Huson and Bryant, 2006). Evidence for recombination between STs was also investigated using split decomposition tree, constructed with 1000 bootstrap replicates based on parsimony splits implemented in SpleesTree4 version 4.12.3.

\section{Phylogenetic analysis}

A neighbor-joining ( $\mathrm{NJ}$ ) tree of concatenated housekeeping genes was constructed based on the $\mathrm{NJ}$ method (Saitou and Nei, 1987) using MEGA5 software (Tamura et al., 2011), with support for branches provided by bootstrapping $(n=1000)$. The e-BURST v3 software was used to divide STs into groups of closely related ones (clonal complexes) (http://pubmlst.org/analysis/). These clonal complexes were statistically assessed by bootstrap method $(n=1000)$ and the analysis was performed with default settings (a minimum of 6 alleles shared) and relaxed settings (a minimum of 5 alleles shared) defining the group parameters.

\subsection{Statistical analysis}

Fisher's exact test is an appropriate statistical test for determining the presence of a non-random association between two categorical variables and was used to check whether the genetic variants of $F$. psychrophilum exhibited a geographical pattern. This statistical test was implemented with SAS software (SAS statistical software version 9.2; SAS Institute Inc., Cary, NC, USA).

\subsection{Nucleotide sequence accession numbers}

Only nucleotide sequences corresponding to new allele types (19 sequences, Table 1) have been deposited in GenBank (accession numbers JQ595418, JQ595419, JQ595424, JQ595426, JQ595429, JQ595431, JQ595433 to JQ595435, JQ595437, JQ595439, JQ595442 to JQ595449).

\section{Results}

4.1. Phenotypic characterization and molecular identification of F. psychrophilum

The 66 selected isolates (Table 1) came from 45 farms (24 in Aquitaine, 17 in Bretagne, 2 in Pays de la Loire and 2 
Table 3

Characteristics, polymorphism and recombination of MLST loci.

\begin{tabular}{|c|c|c|c|c|c|c|c|c|c|c|c|}
\hline \multirow[t]{2}{*}{ Locus } & \multirow[t]{2}{*}{ Size (bp) } & \multicolumn{2}{|c|}{$\begin{array}{l}\text { No. (\%) of variable } \\
\text { sites }\end{array}$} & \multicolumn{2}{|c|}{ No. of types ${ }^{a}$} & \multirow[t]{2}{*}{$H^{\mathrm{b}}$} & \multirow[t]{2}{*}{$\pi\left(b^{-1}\right)^{c}$} & \multirow[t]{2}{*}{$S^{\mathrm{d}}$} & \multirow[t]{2}{*}{$N^{\mathrm{e}}$} & \multirow[t]{2}{*}{$\mathrm{d} N / \mathrm{d} S^{\mathrm{f}}$} & \multirow[t]{2}{*}{$\mathrm{PHI}^{\mathrm{g}}$} \\
\hline & & Total & $\mathrm{New}^{\mathrm{h}}$ & Total & New & & & & & & \\
\hline $\operatorname{trp} B$ & 789 & $5(0.63 \%)$ & 0 & 6 & 2 & 0.5408 & 0.00184 & 7 & 0 & 0.0000 & $0.022^{*}$ \\
\hline gyrB & 1077 & $16(1.48 \%)$ & 0 & 7 & 4 & 0.4033 & 0.00332 & 23 & 0 & 0.0000 & $0.008^{*}$ \\
\hline dnaK & 882 & $9(1 \%)$ & 1 & 7 & 4 & 0.4033 & 0.00176 & 10 & 1 & 0.0020 & $0.041^{*}$ \\
\hline tuf & 795 & $15(1.9 \%)$ & 0 & 8 & 6 & 0.3837 & 0.00512 & 18 & 0 & 0.0000 & 0.806 \\
\hline fumc & 750 & $4(0.53 \%)$ & 0 & 5 & 0 & 0.3795 & 0.00066 & 5 & 0 & 0.2738 & 1 \\
\hline murG & 681 & $9(1.32 \%)$ & 0 & 5 & 1 & 0.5291 & 0.00343 & 7 & 5 & 0.0000 & 0.102 \\
\hline $\operatorname{atp} A$ & 834 & $23(2.7 \%)$ & 1 & 5 & 2 & 0.3795 & 0.00633 & 28 & 1 & 0.0171 & $0.001^{*}$ \\
\hline Concatenate & 5808 & $81(1.4 \%)$ & 2 & 15 & 14 & 0.4313 & 0.00317 & 135 & 9 & 0.0200 & $5.35 \times 10^{-9}$ \\
\hline $\begin{array}{l}\text { a Number of } \\
\text { b Gene diver } \\
\text { c Nucleotide } \\
\text { d Number of } \\
\text { e Number of } \\
\text { f Ratio of no } \\
\text { g Pairwise ho } \\
\text { h New by co } \\
\text { * Statistically }\end{array}$ & $\begin{array}{l}\text { ele types id } \\
\text { ersity per s } \\
\text { honymous s } \\
\text { n-synonym } \\
\text { jnonymous } \\
\text { oplasy indes } \\
\text { arison with } \\
\text { gnificative }\end{array}$ & $\begin{array}{l}\text { stitutions. } \\
\text { substitution } \\
\text { synonymous } \\
\text { e results of } \mathrm{N} \\
\text { e of recombi }\end{array}$ & $\begin{array}{l}\text { Itations } \\
\text { las et a } \\
\text { ion }(p<\end{array}$ & $\begin{array}{l}08) . \\
5) .\end{array}$ & quence & pes iden & d for conca & ate. & & & \\
\hline
\end{tabular}

in Poitou Charente) (Fig. 1). They were negative for the Gram test and positive for the catalase and flexirubin tests. The gyrA/gyrB duplex PCR yielded products with the expected sizes: 396 and $1017 \mathrm{bp}$ respectively (data not shown), confirming the identification of all isolates as $F$. psychrophilum. Amplicons were not observed for negative controls.

\subsection{Analysis of sequence diversity in housekeeping genes}

All seven housekeeping MLST genes of the 66 isolates were successfully amplified and sequenced, and the genetic characteristics of each locus are described in Table 3 . Within the $5808 \mathrm{bp}$ of the concatenated sequence of seven loci in the $66 \mathrm{~F}$. psychrophilum French isolates, 81 polymorphic sites (1.39\% of the positions) were observed. No insertions or deletions were detected within the loci analyzed. The number of single-nucleotide polymorphisms (SNPs) sites between loci varied from 4 (at locus fumC) to 23 (at locus atpA). Compared to the previous study data (Nicolas et al., 2008), new SNPs sites were identified in 2 loci (dnaK and atpA), each of them presenting one new SNP site. All SNPs sites were biallelic, except two that were triallelic (one in tuf and one in gyrB). The average number of allele types per locus was 6.1 (ranging from 5 at loci atpA, fum C and murG, to 8 at locus tuf) and new allele types were detected for all loci, except fumC.

The average gene diversity $(H)$ over the seven loci was 0.4313 , with $\mathrm{H}$ values for individual loci ranging from 0.3795 for atpA and fumC, to 0.5408 for $\operatorname{trpB}$. Pairwise nucleotide diversity $(\pi)$ ranged from 0.00066 for fum $C$ to 0.00633 for atpA, with an average value of 0.00317 . Synonymous substitutions were more common than non-synonymous substitutions, and the ratio of non-synonymous to synonymous mutations $(\mathrm{d} N / \mathrm{d} S)$ was less than 1 for all loci, with $\mathrm{d} N / \mathrm{d} S$ equal to 0 for $\operatorname{mur} G$, gyrB, $\operatorname{trp} B$, and tuf, while ranging from 0.0020 to 0.2738 for the three other genes. A dN/dS ratio less than 1 indicates that the diversity present in all these genes is likely driven by purifying selection.

\subsection{Analysis of recombination events}

When the occurrence of recombination in each locus was investigated by PHI test, the results showed statistically significant recombination for four loci (atpA, dnaK, gyrB and $\operatorname{trpB}$ ) (Table 3). Application of the PHI test to the concatenated sequences revealed statistically significant evidence of recombination $(p<0.05)$. To test further for recombination traces, SplitsTree program was used on

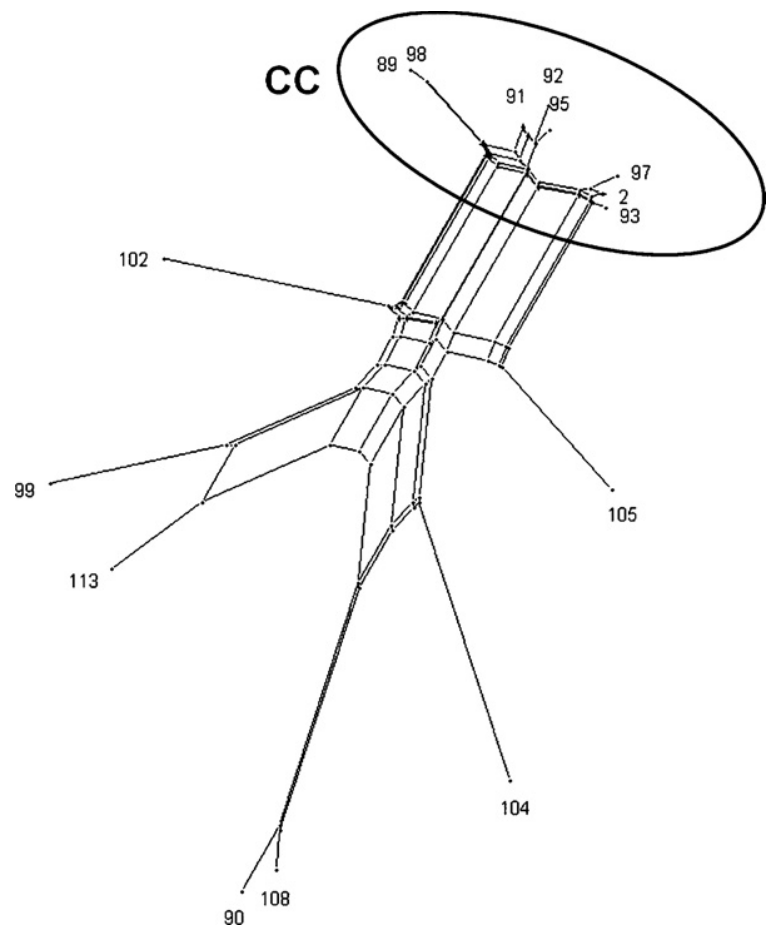

Fig. 2. Split decomposition analysis. The tree was constructed under neighbor net graph option, with the concatenated sequences of each ST. STs of the clonal complex are circled. 
concatenated sequence of all STs. This analysis showed a bushy network structure indicative of recombination events (Fig. 2). Evidence of recombination was also assessed from the standardized index of association $\left(I_{\mathrm{A}}^{S}\right)$. This statistical clonality test attempts to measure the extent of linkage disequilibrium within a population by quantifying the amount of recombination occurring between a set of sequences and detecting association between alleles at different loci and gives indication on population structure (clonal, panmictic, or epidemic). Here, the entire dataset of $F$. psychrophilum isolates yielded an $I_{A}^{S}$ of 0.6088 , significantly different from $0(p<0.05)$. A lower value differing significantly from $0(p<0.05)$ was obtained when the dataset of all single representatives of each of the 15 STs retrieved by MLST (Table 3) was analyzed $\left(I_{\mathrm{A}}^{\mathrm{S}}=0.4567\right)$, indicating a linkage disequilibrium. This linkage disequilibrium disappears when STs are divided in clusters of genetically related STs (Supplementary data $S 1$ ), with $I_{A}^{S}$ value that drops sharply down to 0.084 , significantly close to $0(p>0.05)$.

\subsection{Phylogenetic relatedness of French F. psychrophilum isolates}

This MLST study identified 15 STs among the 66 French F. psychrophilum isolates analysed, 14 of which have not been described before (Table 1 and Table 3 ). The STs occurred at unequal frequencies. The majority of STs (11/ 15) was found only once, each representing $1.51 \%$ of the total isolates, and the genetic variant most frequently encountered was ST2, representing $46.9 \%$ of the total isolates. The other most common genetic variants were ST90, ST89 and ST92 (7.5-15.5\% of the total sample).

The predicted evolutionary descent of the 66 isolates was then investigated by clustering method, eBURST (Feil et al., 2004), using a default group definition in which STs differing at only one single locus (single locus variant or SLV) are grouped together. With these default parameters, STs that are linked share six common locus types and are grouped in a clonal complex at the center of which, a founder (common ancestor) is predicted. When this method was applied to our sample, the 15 STs retrieved could be divided into one clonal complex or CC (composed of 8 STs and representing $75.7 \%$ of the total isolates) and 7 singletons STs (Fig. 3). ST2 was identified as the potential founder and was connected with ST89, ST93, ST97 ST98 and ST91 which also shared alleles with ST92 and ST95. F. psychrophilum reference strains JIP 02/86 (isolated from rainbow trout) and $\mathrm{NCIMB} 1947^{\mathrm{T}}$ (isolated from coho salmon) were added in analysis in order to highlight possible relationship with French isolates. e-BURST analysis including JIP 02/86 and NCIMB $1947^{\mathrm{T}}$ respectively ST20 and ST13, show those STs as singleton.

The relatedness between STs can also be expressed by relaxed parameter that shows all pairs of STs sharing two ATs. ST20, the reference strain JIP 02/86 ST showed connections with ST2, ST93 and ST97. On the other hand, this relaxed double locus variants (DLV) criterion revealed that ST90 was linked to ST108.

The phylogenetic relationship between isolates was further analyzed by constructing a NJ unrooted tree, using

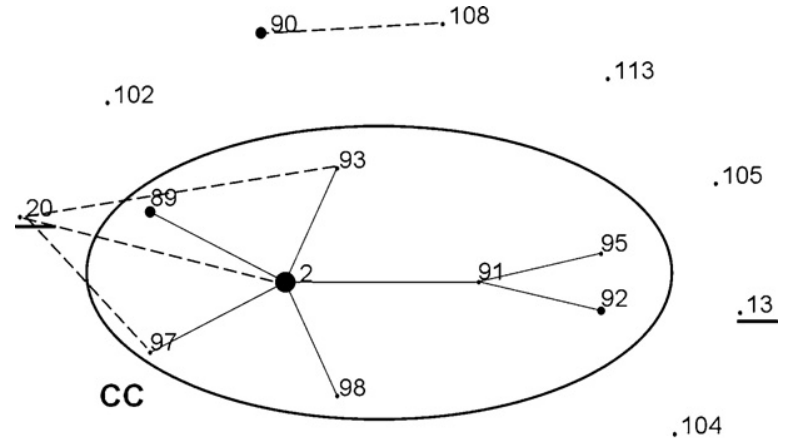

.99

Fig. 3. eBURST diagram. Single locus variants (sequence types that differ by one allele type) are joined by straight lines, and circled in the same clonal complex (CC). Double locus variants (sequence types that differ by two allele types) are joined by dotted lines. Dot sizes are proportional to the number of isolates within each ST, and the bigger one is the founder of the CC, ST2. The underlined STs, ST13 and ST20, are the genotypes of reference strains NCIMB $1947^{\mathrm{T}}$ and JIP 02/86 respectively.

the number of differences method. This tree was constructed from the concatenated nucleotide sequences of the seven loci in all 66 isolates and of the reference strains JIP 02/86 and NCIMB $1947^{\mathrm{T}}$ (Fig. 4). The CC revealed by eBURST analysis was apparent as cluster on the phylogenetic tree, with good percentage values of the bootstrap support (Fig. 4). Examination of the NJ tree showed that very diverse STs could be found within a given French region. This was confirmed by applying an exact Fisher test to the $F$. psychrophilum sample. The presence and the absence of ST2 in the four French regions studied, as it is the most represented ST, were tested and the Fisher exact test did not reveal any significant geographical pattern in the distribution of the ST2 isolates $(p<0.05)$.

\section{Discussion}

MLST has emerged as the technique of choice for studying the population structure of many bacterial species (Maiden, 2006). This typing method became possible as a result of access to DNA sequences of bacteria. In the case of the recognized threat of $F$. psychrophilum to the salmonid farming industry, the recent publication of the complete genome sequence of this bacterium (Duchaud et al., 2007) had already led to the development of a MLST scheme (Nicolas et al., 2008). In the present study, we used the 7 loci ( $\operatorname{trp} B, \operatorname{gyr} B, \operatorname{dnaK}$, fumC, murG, tuf, and $\operatorname{atpA}$ ) from this previously published MLST scheme to gain insight into the genetic diversity of clinical isolates of F. psychrophilum collected from rainbow trout farmed in France.

Analysis of the pattern of polymorphism in the entire dataset revealed a few polymorphic sites, characterized by low concatenate sequence nucleotide diversity per site $(\pi \times 100=0.31 \%)$ and weak average gene diversity $(H=0.4313)$. When the same seven MLST loci considered in the present study were analysed in light of the data of Nicolas and colleagues (2008), obtained for twenty four 


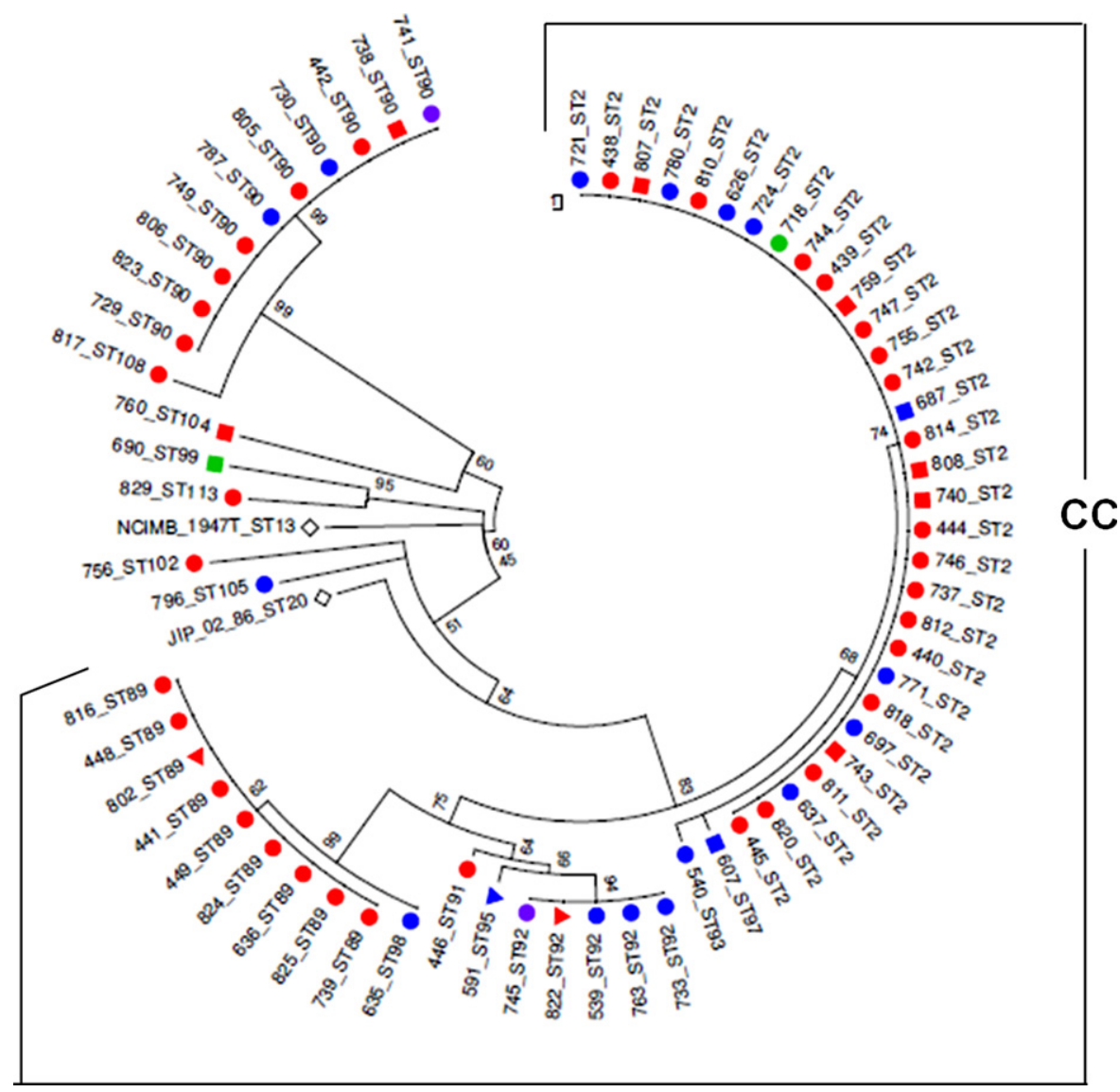

Fig. 4. Neighbor-joining unrooted tree of 66 French F. psychrophilum isolates, including F. psychrophilum reference strain JIP $02 / 86$ and NCIMB $1947^{\mathrm{T}}$. For each isolate, the French region, the tissue location and ST number are indicated. The evolutionary distances were computed using the number of differences method and are in the units of the number of base substitutions per site. French regions are indicated by different colors: Aquitaine in red, Bretagne in blue, Poitou Charentes in violet, and Pays de la Loire in green. Tissue locations are represented by different forms: internal by a circle, external by a square and unknown tissue by a triangle. Reference strains are indicated by diamonds. (For interpretation of the references to color in this figure legend, the reader is referred to the web version of this article.)

isolates from rainbow trout collected worldwide over a period of 14 years, the same order of gene diversity $(H=0.5333)$ was observed. Thus the French rainbow trout isolates exhibited almost as much diversity as the diversity observed in rainbow trout isolates from previously examined countries, thereby emphasizing the strong association between genetically closely related isolates and the rainbow trout host, as discussed below.

Clonal populations are identified by an $I_{\mathrm{A}}^{S}$ value that differs significantly from zero and population under panmixia has an $I_{A}^{S}$ value close to zero. Limited and nonrandom sampling may lead to over-representation of particular STs, as in this study, and to the observation of a "clonal" population structure (Smith et al., 1993). This problem can be avoided by using single representatives of each ST as units for $I_{A}^{S}$ measurement. On the other hand, Smith et al. (1993) demonstrated that when STs are divided into clusters of genetically related STs and each cluster is treated as a unit (Caugant et al., 1987), an epidemic structure of the population can be observed. In this case, the clonal structure observed for the entire dataset of the isolates and the all single representatives of each STs disappears. Here, the $I_{\mathrm{A}}^{\mathrm{S}}$ value was significantly higher than $0\left(I_{\mathrm{A}}^{S}=0.6088, p<0.05\right)$ for all $66 \mathrm{~F}$. psychrophilum samples which indicates that the alleles were in strong disequilibrium. The $I_{A}^{S}$ value for the $15 \mathrm{STs}$ $\left(I_{\mathrm{A}}^{S}=0.4567, p<0.05\right)$ was lower than 0 for the full dataset of 66 isolates, indicating that the number of recombination events which did not strongly affect the linkage between alleles was limited and attesting the possible clonal population structure of $F$. psychrophilum rainbow trout isolates in France. Equivalent $I_{A}^{S}$ values were re-calculated from the data of Nicolas et al. (2008), and are globally similar to our data: 0.5984 for the entire sample ( 50 isolates) and 0.4936 using single representatives of the STs as units, both values being significantly higher than 0 . However, when STs were clustered according to their genetic relatedness, the clonal structure of our sample disappeared $\left(I_{\AA}^{S}=0.084, \quad p>0.05\right)$, revealing an epidemic structure of the population. A similar example was observed with Neisseria meningitidis where the analyzed population appeared first clonal despite recombination events, to finally prove to be epidemic after $I_{A}^{S}$ calculation following clustering (Smith et al., 1993). This demonstrates 
the epidemic structure of the F. psychrophilum population analyzed here.

Those data emphasizes that the genetic diversity in $F$. psychrophilum was mainly driven by homologous recombination, as previously demonstrated (Nicolas et al., 2008; Vos and Didelot, 2008). Moreover, PHI values for the concatenate sequences, which differed significantly from zero, supported the recombinogenic nature of $F$. psychrophilum. The PHI test also indicated that atpA, dnaK, gyrB and $\operatorname{trp} B$ are the housekeeping genes which induced diversity through recombination. This is consistent with the observed conflicts on the trees at the different loci (Supplementary data S2), and strongly indicative of the role of homologous recombination in the generation of diversity in F. psychrophilum, also deducible by the bushy network structure done by split decomposition analysis.

The recently published MLST analysis of Aeromonas spp. (A. hydrophila, A. bestiarum, A. salmonicida, A. caviae, A. media, A. eucrenophila, A. sobria, A. veronii, A. jandaei, A. schubertii, A. enteropelogenes, A. encheleia, A. allosaccharophila, $A$. popoffii, and $A$. sharmana) commonly isolated from diseased and healthy fish, showed a very different pattern (Martino et al., 2011). Although the genetic diversity was very high, the methods used to detect evidence of recombination indicated that the intra-specific recombination was very low. This was the case for $A$. veronii, although a relevant effect of recombination was reported in another study (Silver et al., 2011). Thus, the different sampling schemes and methodologies used to detect bacterial recombination also clearly influence the conclusions drawn. In the present case of $F$. psychrophilum, recombination was shown to be a major evolutionary force driving genetic diversity in the French ecological niche, as observed worldwide (Nicolas et al., 2008).

Conjugating plasmids, phages and transposons that require bacterial competence, are the three vectors involved in bacterial recombination. Plasmids (Alvarez et al., 2004; Duchaud et al., 2007), a number of $F$. psychrophilum bacteriophages (Kim et al., 2010) and transposons (Alvarez et al., 2004) have been identified on $F$. psychrophilum but their involvement in recombination of this bacterium remains unknown.

In the present study, 15 sequence types were identified, including 14 new STs derived from only 2 additional single nucleotide polymorphic (SNP) sites. This implies that most of the described allele diversity originated from new intragenic associations of previously described SNPs, thus supporting the important role of homologous recombination in the evolution of this bacterium. The eBURST analysis with SLV criterion separated the 15 STs detected into one clonal complex (CC) where ST2 was identified as the primary founder, and several STs that did not share any similarity with this CC. In a previous publication (Nicolas et al., 2008), three clonal complexes (CC1, CC2 and CC3) had been detected and CC1 was also shown to have ST2 (isolated only from rainbow trout) as its primary founder. CC1 and CC can therefore be considered as similar. No members of the previously described CC2 and CC3 were identified in our isolates. With DLV criterion, analysis including the reference strains JIP 02/86 and NCIMB $1947^{\mathrm{T}}$, showed that only the ST (ST20) of the reference strain isolated from rainbow trout (JIP 02/86) shared ATs with STs included in the CC.

The occurrence of identical STs in geographically distant areas (worldwide) as described previously (Nicolas et al., 2008), and highlighted in Fig. 1, by the NJ tree (Fig. 4) and the statistical test, suggests a likely role of brood fish, egg fish and fish trading in the dissemination of $F$. psychrophilum, at least for some specific STs. Moreover, ST2 seems to be strongly associated to rainbow trout as it has only been found in this fish species (Nicolas et al., 2008). However, many singletons STs have also been characterized in rainbow trout both worldwide ( 8 in the study of Nicolas et al., 2008) and in France ( 7 in the present study). One explanatory hypothesis for the presence of these singletons STs, might be that these STs are not linked to the trading of salmonid products but are related to endemic isolates. Those endemic isolates might occur rarely and/or could be less virulent than the others or less well adapted to the rainbow trout species. Indeed $F$. psychrophilum has been found in water (Madetoja and Wiklund, 2002) and non-fish host that could act as reservoir (Amita et al., 2000; Izumi et al., 2005). Natural fish population can also serve as reservoirs of $F$. psychrophilum, and it was shown that the associated bacteria could demonstrate a greater genetic variability than observed in reared fish population (Chen et al., 2008). Then horizontal transmission through circulating water could be assumed. A detailed study of the genetic diversity of isolates on a more limited geographic scale (a fish farm) might reveal local clonal complexes otherwise masked by the CC1 members over-distributed as a result of fish trade.

In conclusion, MLST analysis supports the hypothesis of an epidemic population structure of this bacterium due mainly to the expansion of genetically closely related isolates. Additional analyses are now required to complete our knowledge of the genetic variants present at an even smaller geographical scale (a farm for example), to examine if singleton STs represent local and environmentally associated types with a local clonal structure. Such analyses could be simplified by designing an allele-specific real-time PCR for the most informative SNPs on each locus (Sheludchenko et al., 2010). As shown in the present study, very few new polymorphic sites were found in the 66 isolates analyzed (only 2 on the $429 \mathrm{kbp}$ sequenced in this study), and the finding of new SNPs will probably be rare in this context (rainbow trout as host fish studied in France). A bar-coding technique would avoid the expensive and labor-consuming step of systematic sequencing and could be applied to a large set of isolates.

\section{Acknowledgements}

We are grateful to Pierre Nicolas (INRA, Jouy-en Josas, France) for assembling the sequences, attributing the ATs and STs (Allele and Sequence Types attributions), and fruitful discussions. We would like to thank Catherine Mangion, Michaëlle Larhantec and Isabelle Perray for their technical support, and Anne Lehébel for her help with statistical questions. We are also grateful to $\mathrm{H}$. Seegers and L. Malandrin from the UMR BioEpAR for their advice during C. Siekoula-Nguedia's PhD thesis and their critical reading 
of this manuscript. Thanks to the "Plateau Fédératif de Biologie Moléculaire" of Oniris for providing the equipment for carrying out the experiments, to the "Agence Nationale de la Recherche" of France for 07-GMGE grant that supported the equipments dedicated to sequence treatments, and to France AGRIMER (constitution of the isolates collection). C.S.N.'s PhD thesis was supported by grants from the "Pays de la Loire" region, INRA and UMR BioEpAR.

\section{Appendix A. Supplementary data}

Supplementary data associated with this article can be found, in the online version, at http://dx.doi.org/10.1016/ j.vetmic.2012.07.022.

\section{References}

Alvarez, B., Secades, P., McBride, M.J., Guijarro, J.A., 2004. Development of genetic techniques for the psychrotrophic fish pathogen Flavobacterium psychrophilum. Appl. Environ. Microbiol. 70, 581-587.

Amita, K., Hoshino, M., Honma, T., Wakabayashi, H., 2000. An investigation on the distribution of Flavobacterium psychrophilum in the Umikawa river. Fish Pathol. 35, 193-197.

Bruen, T.C., Philippe, H., Bryant, D., 2006. A simple and robust statistical test for detecting the presence of recombination. Genetics 172 , 2665-2681.

Caugant, D.A., Mocca, L.F., Frasch, C.E., Frøholm, L.O., Zollinger, W.D., Selander, R.K., 1987. Genetic structure of Neisseria meningitidis populations in relation to serogroup, serotype, and outer membrane protein pattern. J. Bacteriol. 169, 2781-2792.

Cepeda, C., García-Márquez, S., Santos, Y., 2004. Improved growth of Flavobacterium psychrophilum using a new culture medium. Aquaculture 238, 75-82.

Chen, Y.C., Davis, M.A., LaPatra, S.E., Cain, K.D., Snekvik, K.R., Call, D.R. 2008. Genetic diversity of Flavobacterium psychrophilum recovered from commercially raised rainbow trout, Oncorhynchus mykiss (Walbaum), and spawning coho salmon, O. kisutch (Walbaum). J. Fish Dis. $31,765-773$.

Duchaud, E., Boussaha, M., Loux, V., Bernardet, J.-F., Michel, C., Kerouault, B., Mondot, S., Nicolas, P., Bossy, R., Caron, C., Bessieres, P., Gibrat, J.-F., Claverol, S., Dumetz, F., Le Henaff, M., Benmansour, A., 2007. Complete genome sequence of the fish pathogen Flavobacterium psychrophilum. Nat. Biotechnol. 25, 763-769.

Ewing, B., Green, P., 1998. Base-calling of automated sequencer traces using Phred. II. Error probabilities. Genome Res. 8, 186-194.

Ewing, B., Hillier, L., Wendl, M.C., Green, P., 1998. Base-calling of automated sequencer traces using Phred. I. Accuracy assessment. Genome Res. 8, 175-185.

Feil, E.J., Li, B.C., Aanensen, D.M., Hanage, W.P., Spratt, B.G., 2004. eBURST: inferring patterns of evolutionary descent among clusters of related bacterial genotypes from multilocus sequence typing data. J. Bacteriol. 186, 1518-1530.

Gordon, D., Abajian, C., Green, P., 1998. Consed: a graphical tool for sequence finishing. Genome Res. 8, 195-202.

Guichard, B., 2004. Principaux résultats de l'enquête "Pathologie de poissons 2004". Bull. Epidémiol. Santé Anim. Alim. 15, 5-6.

Hall, T.A., 1999. BioEdit: a user-friendly biological sequence alignment editor and analysis program for Windows 95/98/NT. Nucleic Acids Symp. Ser. 41, 95-98.
Huson, D.H., Bryant, D., 2006. Application of phylogenetic networks in evolutionary studies. Mol. Biol. Evol. 23, 254-267.

Iida, Y., Mizokami, A., 1996. Outbreaks of coldwater disease in wild ayu and pale chub. Fish Pathol. 31, 157-164.

Izumi, S., Aranishi, F., 2004. Relationship between gyrA mutations and quinolone resistance in Flavobacterium psychrophilum isolates. Appl. Environ. Microbiol. 70, 3968-3972.

Izumi, S., Fujii, H., Aranishi, F., 2005. Detection and identification of Flavobacterium psychrophilum from gill washings and benthic diatoms by PCR-based sequencing analysis. J. Fish Dis. 28, 559-564.

Izumi, S., Wakabayashi, H., 2000. Sequencing of gyrB and their application in the identification of Flavobacterium psychrophilum by PCR. Fish Pathol. 35, 93-94.

Jolley, K.A., Feil, E.J., Chan, M.-S., Maiden, M.C.J., 2001. Sequence type analysis and recombinational tests (START). Bioinformatics 17, 1230-1231.

Kim, J.H., Gomez, D.K., Nakai, T., Park, S.C., 2010. Isolation and identification of bacteriophages infecting ayu Plecoglossus altivelis altivelis specific Flavobacterium psychrophilum. Vet. Microbiol. 140, 109-115.

Lehmann, J., Mock, D., Stürenberg, F.-J., Bernardet, J.-F., 1991. First isolation of Cytophaga psychrophila from a systemic disease in eel and cyprinids. Dis. Aquat. Organ. 10, 217-220.

Li, W., Raoult, D., Fournier, P.E., 2009. Bacterial strain typing in the genomic era. FEMS Microbiol. Rev. 33, 892-916.

Librado, P., Rozas, J., 2009. DnaSP v5: a software for comprehensive analysis of DNA polymorphism data. Bioinformatics 25, 1451-1452.

Madetoja, J., Wiklund, T., 2002. Detection of the fish pathogen Flavobacterium psychrophilum in water from fish farms. Syst. Appl. Microbiol. $25,259-266$.

Maiden, M.C.J., 2006. Multilocus sequence typing of bacteria. Annu. Rev. Microbiol. 60, 561-588.

Martino, M.E., Fasolato, L., Montemurro, F., Rosteghin, M., Manfrin, A. Patarnello, T., Novelli, E., Cardazzo, B., 2011. Determination of microbial diversity of Aeromonas strains on the basis of multilocus sequence typing, phenotype, and presence of putative virulence genes. Appl. Environ. Microbiol. 77, 4986-5000.

Nematollahi, A., Decostere, A., Pasmans, F., Haesebrouck, F., 2003. Flavobacterium psychrophilum infections in salmonid fish. J. Fish Dis. 26, 563-574.

Nicolas, P., Mondot, S., Achaz, G., Bouchenot, C., Bernardet, J.-F., Duchaud, E., 2008. Population structure of the fish-pathogenic bacterium Flavobacterium psychrophilum. Appl. Environ. Microbiol. 74, 3702-3709.

Plant, K.P., LaPatra, S.E., Cain, K.D., 2009. Vaccination of rainbow trout Oncorhynchus mykiss (Walbaum), with recombinant and DNA vaccines produced to Flavobacterium psychrophilum heat shock proteins 60 and 70. J. Fish Dis. 32, 521-534.

Saitou, N., Nei, M., 1987. The neighbor-joining method: a new method for reconstructing phylogenetic trees. Mol. Biol. Evol. 4, 406-425.

Schmidt, A.S., Bruun, M.S., Dalsgaard, I., Pedersen, K., Larsen, J.L., 2000. Occurrence of antimicrobial resistance in fish-pathogenic and environmental bacteria associated with four Danish rainbow trout farms. Appl. Environ. Microbiol. 66, 4908-4915.

Sheludchenko, M.S., Huygens, F., Hargreaves, M.H., 2010. Highly discriminatory single-nucleotide polymorphism interrogation of Escherichia coli by use of allele-specific real-time PCR and eBURST analysis. Appl. Environ. Microbiol. 76, 4337-4345.

Silver, A.C., Williams, D., Faucher, J., Horneman, A.J., Gogarten, J.P., Graf, J., 2011. Complex evolutionary history of the Aeromonas veronii group revealed by host interaction and DNA sequence data. PLoS One 6, e16751.

Smith, J.M., Smith, N.H., O’Rourke, M., Spratt, B.G., 1993. How clonal are bacteria? Proc. Natl. Acad. Sci U.S.A. 90, 4384-4388.

Tamura, K., Peterson, D., Peterson, N., Stecher, G., Nei, M., Kumar, S., 2011. MEGA5: molecular evolutionary genetics analysis using maximum likelihood evolutionary distance, and maximum parsimony methods. Mol. Biol. Evol. 28, 2731-2739.

Vos, M., Didelot, X., 2008. A comparison of homologous recombination rates in bacteria and archaea. ISME J. 3, 199-208. 